\title{
Forensic Evaluation of Compacted Soils using RAMCODES
}

\author{
Romer D. Oyola-Guzmán ${ }^{a^{*}}$, Rómulo Oyola-Morales ${ }^{\mathrm{b}}$ \\ ${ }^{a}$ Centro de Investigación en Ciencia Aplicada y Tecnología Avanzada del Instituto Politécnico Nacional. Legaria 694, Col. Irrigación. \\ CDMX, 11500, México. \\ ${ }^{b}$ Universidad Autónoma Gabriel René Moreno, Facultad Politécnica. Av. Ejército Nacional s/n, Santa Cruz de la Sierra, Bolivia
}

Received 30 August 2018; Accepted 09 October 2018

\begin{abstract}
Unexpected failure of compacted soils was explained using design curves of the Rational Methodology for Compacted Geomaterial's Density and Strength Analysis (RAMCODES). Forensic geotechnical evaluation, applied to a compacted soil used at a construction site, demonstrated that the bearing capacity of the soil was influenced by the water content and the dry unit weight. At the construction site, the only criterion used for quality control of the compacted soil was the minimum compaction percentage; the maximum dry unit weight (achieved using the standard Proctor test) was used when the soil was compacted with light equipment, and the maximum dry unit weight (achieved using the modified Proctor test) was used when it was compacted with heavy equipment. After changing water content conditions, the soil compacted with heavy equipment and the soil compacted with light equipment exhibited changes in bearing capacity; the soil compacted with light equipment showed a failure, whereas the soil compacted with heavy equipment did not. The causes of failure were evaluated from samples of soil analyzed in the laboratory; analysis was performed using design curves obtained through a factorial experimental design. Our analysis revealed that the criterion of minimum compaction percentage was not adequate to determine the actual mechanical performance of the soil. We sought to determine why the soil compacted with light equipment did not satisfy the bearing capacity expected after compaction, and what other actions should performed at a construction site to avoid failure of soils compacted with light equipment.
\end{abstract}

Keywords: Soil Failure; Base Course; RAMCODES; Design Curves; Compacted Soils; Quality Control.

\section{Introduction}

Specifications for quality control of compacted soils are frequently based on a minimum compaction percentage [1, 2]. The compaction percentage is defined as the ratio between the dry unit weight measured at the construction site and the maximum dry unit weight measured in the laboratory. The maximum dry unit weight used as a reference for the compaction percentage can be obtained in the laboratory using a pre-defined compactive effort (i.e. standard Proctor or modified Proctor tests). Although the minimum compaction percentage does not measure a mechanical property [3], it is strongly ingrained in the verification process of quality control of compacted soils [2, 4]. For instance, Hilf [5] states that the use of "the simpler density and moisture measurements has been generally accepted for field control".

In 1987 Hermann and Elsbury [6] suggested that, for compacted soils destined to resist load, the minimum compaction percentage should be at least $95 \%$ of the maximum dry unit weight obtained by the standard Proctor test, or $90 \%$ of the dry unit weight obtained by the modified Proctor test. However, this suggestion has been considered as an unbreakable rule by many Latin American designers and constructors [7]; once a minimum compaction percentage is achieved, it is assumed that the mechanical performance of the compacted soil will be optimum $[2,8]$.

\footnotetext{
* Corresponding author: royolag1500@alumno.ipn.mx
}

\section{doi http://dx.doi.org/10.28991/cej-03091157}

$>$ This is an open access article under the CC-BY license (https://creativecommons.org/licenses/by/4.0/).

(C) Authors retain all copyrights. 
The standards ASTM D698 [9] and ASTM D1557 [10] of the American Society of Testing Materials, suggest that the necessary compaction percentage should be determined according to previous experiences and/or experimentation; however, these standards do not propose specific experimental methodology for this purpose.

The Venezuelan norm [11] established that, for quality control of compacted soils, it is possible to use resistance maps as an alternative to the minimum compaction percentage. Resistance maps are obtained through factorial experimental designs, using the soil that will be used in the compaction process (annex B of the COVENIN norm); this methodology is called Rational Methodology for Compacted Geomaterial's Density and Strength Analysis, known by its acronym RAMCODES [12].

According to Sánchez-Leal et al. [12], the RAMCODES methodology is applicable to the measurement of any mechanical response of a soil in the laboratory (e.g. California Bearing Ratio, compressive strength, shear strength), as well as to the measurement of more sophisticated variables (i.e. resilient module, cyclic shear strength). Despite this advantage RAMCODES still competes with "the weight of the tradition"; for example, in Bolivia and other Latin American countries, the minimum compaction percentage is commonly established according to the "historical focus" represented by the information present in engineering text books $[12,13]$.

According to the historical focus, the compactive effort for compaction tests in the laboratory (e.g. Proctor test) is frequently chosen according to the equipment that will be used in the compaction process [14, 15]. Almost as a general rule, and as an implicitly accepted agreement, when motor-powered equipment is used (e.g. compact rolls with a mass generally over $8 \mathrm{Mg}$, heavy equipment), a compactive effort of $2700 \mathrm{~kJ} / \mathrm{m}^{3}$ is chosen (modified Proctor test), but when light equipment is used, the compactive effort chosen for compaction is $600 \mathrm{~kJ} / \mathrm{m}^{3}$ (standard Proctor test) [7].

In 1933 Proctor [16] established that the maximum dry unit weight obtained in the laboratory depends on the compactive effort used in the compaction process [9-10]. Thus, the maximum dry unit weight obtained in the laboratory directly affects the compaction percentage, assessed during quality control of the compacted soil at the construction site. Even if the minimum compaction percentage is fulfilled, when a failure appears in compacted soils, it can be extremely difficult to determine the cause of the failure, and to explain it, using only the specifications (i.e. particle size analysis, consistency limits and the minimum compaction percentage).

The RAMCODES methodology for soil compaction design proposes three levels of design [12]. The first level involves the material's specifications (i.e. particle size analysis, plasticity and minimum compaction percentage) (called code driven). The second level (called field response) takes into account the performance of the material in the field. The third level takes into account the design curves obtained from laboratory tests performed with control suction and uncontrolled suction. Design curves provide valuable information based on the mechanical performance of the material because the mechanical performance of soils is measured in different conditions of water content and dry unit weight [17-18]. These three levels are considered independent, but as a group, they constitute a powerful tool in the design, study, quality control of compacted soils [12, 19-20], and other novel purposes as proposed by the present research (i.e. forensic evaluation of compacted soils).

Additionally, RAMCODES has a section for soil classification: the characteristic factor (Fp), which is defined as a non-dimensional number involving particle size and plasticity properties [12]. This tool provides a quantitative and continuous classification of soils that allows to correlate the index properties (i.e. particle size analysis and plasticity) with the densification potential (i.e. maximum dry unit weight and optimum water content) and with the mechanical response of the compacted soil (e.g. California Bearing Ratio, CBR) [12, 14].

Although the RAMCODES methodology is mostly used for the design of compacted soils, because provide technical and quantitative evidence of the influence of the dry unit weight and the saturation degree on the mechanical performance of compacted soils, in this study the design curves of the RAMCODES methodology were used to explain the cause of failure of a compacted soil, whose compaction quality control was only verified by the minimum compaction percentage. Design curves were obtained from results of laboratory tests, which were processed and plotted using commercial software for graphic and data plotting. This study clearly illustrates how the design curves could be used in forensic geotechnical evaluation, in addition to their use for the design of compacted soils.

\section{Materials and Methods}

\subsection{Materials}

The soil used in this study was collected from two sections of the base course of a street that would be later paved with hydraulic concrete. The construction site was located inside the private housing complex "Colinas del Urubó" (west of Santa Cruz City, Bolivia). Descriptively, the soil was labeled as: "optimum performance soil" and "weak soil".

\subsubsection{Origin and Specifications of the Compacted Soil}

The soil used as base course of pavement at the construction site was provided by a construction material production 
plant. According to the register certificate, the compacted soil met particle size and plasticity standards as required by the private company in charge of the construction of the street. In addition, according to the reception certificate, the company in charge of soil compaction fulfilled the requirements of optimum water content and minimum compaction percentage, of at least $95 \%$ of the maximum dry unit weight obtained with the modified Proctor test.

\subsubsection{Modification of the Compacted Soil}

The register certificate of the construction site mentioned that after the soil was compacted with heavy equipment, part of the compacted soil was removed to make room for a pipe with optic fiber, as requested by the owner of the construction site. An excavation of $1 \mathrm{~m}$ of width and $1 \mathrm{~m}$ of depth was performed, the pipe with the cables was placed, and the excavation re-filled with the soil that was originally removed from the excavation (avoiding mixings the natural material with the base course material). After placing the optic fiber pipe, the soil was compacted with light vibrocompaction equipment (jumping jacks), due to the difficulty of using heavy equipment within the site of excavation.

According to the register certificate, the water content of the soil used as filling was close to the optimum water content determined by the standard Proctor test. Additionally, the dry unit weight was verified to fulfill the criterion of minimum compaction percentage $\geq 95 \%$, with respect to the maximum dry unit weight obtained with the standard Proctor test.

As mentioned in the register certificate of the construction site, the company in charge of soil compaction used the densification potential (optimum water content and maximum dry unit weight obtained with the standard Proctor test) for controlling the compaction percentage because light equipment (jumping jacks) was used for compaction at the construction site [15]. Thus the minimum compaction percentage was not calculated with the maximum dry unit weight obtained with the modified Proctor test.

\subsubsection{Bearing Capacity of the Soil used as Filling in the Excavation}

According to the register certificate of the construction site, before the paving and after two rainy days, a light vehicle drove over the soil compacted with heavy equipment (optimum performance soil) and the soil compacted with light equipment (excavation filling), resulting in the failure of the bearing capacity only of the soil compacted with light equipment.

\subsection{Experimental Methodology}

The data of the soil used in the compaction process (particle grain size, consistency limits, water content, dry unit weight, compaction percentage, and CBR) provided by the private company responsible for the construction was verified experimentally in the laboratory by the authors of this research.

\subsubsection{Sample Collection}

Two samples of the soil that forms the base course of the pavement were obtained, one sample was from a section of optimum performance soil and the other sample was from the section of soil presenting the failure of bearing capacity.

During the design of the pavement structure for the street that would later experience a failure, the engineer established the following characteristics for the base course soil: minimum CBR required $\geq 25 \%$, saturation degree 60 $90 \%$, minimum compaction percentage $\geq 95 \%$ relative to the maximum dry unit weight obtained with the modified Proctor test.

\subsubsection{Mechanical Characterization of the Soils}

The weak soil and the optimum performance soil were submitted to grain particle size analysis [21] analysis of consistence limits [22] and specific gravity [23]. The soils were classified according to RAMCODES methodology [12] and to classification of soils for highway construction purposes [24]. Additionally, the weak soil and the optimum performance soil were submitted to water content tests [25]; dry unit weight was also evaluated using the sand-cone test for weak and optimum performance soil [26]. Afterwards, the null hypothesis of the index properties of the materials was accepted, at a significance level of 0.05 .

\subsubsection{Experimental Design}

An experimental design of four factors (compaction energy) with six levels of treatment (water content) was established [27]. The configuration of the variables was set in a way that allowed easily obtaining specimens with a saturation degree 60-100\% (Figure 1a). According to the proposed experimental design, 24 compaction states were obtained for analysis. 

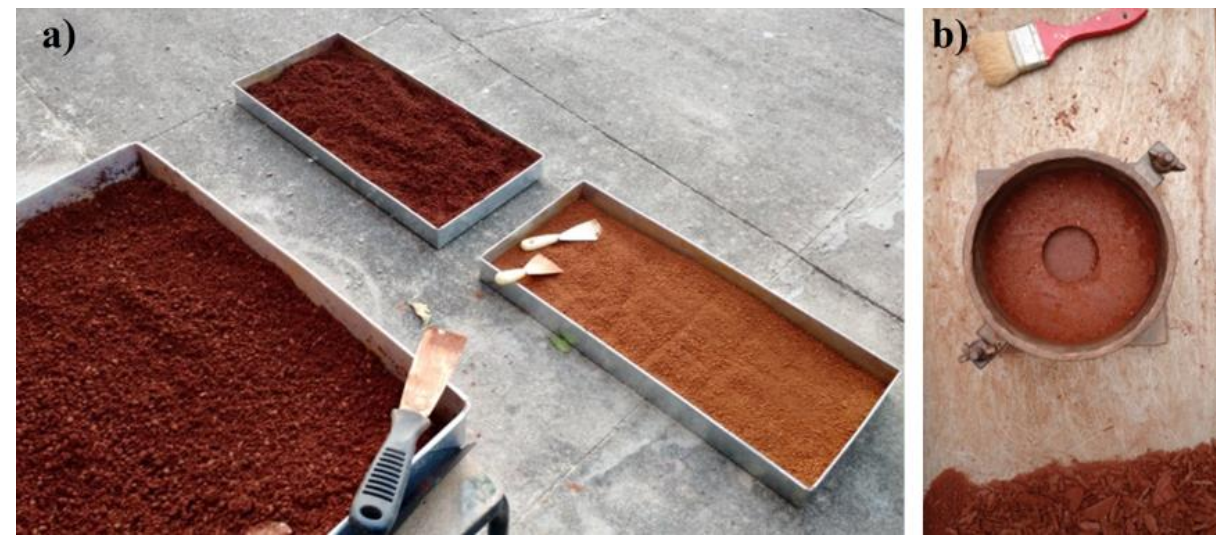

Figure 1. a) Samples with different water content. b) CBR specimen after performance of unsoaked CBR

\subsubsection{Measuring of Mechanical Performance of the Soil}

Bearing capacity (CBR) was measured in 24 different compaction states (different dry unit weight and different water content) at constant rate of penetration and constant surcharge of weights (Figure 1b) [28].

\subsubsection{Data Plotting}

Plots of the surface of the response linking the variables water content ( $\mathrm{X}$ axis), dry unit weight (Y axis), and CBR ( $\mathrm{Z}$ axis) were obtained using a commercial software for graphics and data plotting. The Kriging correlation was used for gridding, with 40 columns and rows, a search radius of 2 , and a smoothing of 0.9 .

\subsubsection{Generation of the Design Curves}

CBR laboratory tests were carried out with uncontrolled suction. Hence, the design curves were obtained intersecting CBR contour curves with curves of different saturation degrees. This information was then represented in graphs where dry unit weight corresponds to the $\mathrm{X}$ axis and the values of the CBR correspond to the $\mathrm{Y}$ axis [13].

\section{Results}

Table 1 shows the results of the tests performed for the mechanical characterization of the material descriptively named weak soil and the optimum performance soil. Table 1 shows the compaction percentage that was obtained during quality control at the construction site (before water content changes in soil). In Table 1, the compaction percentage refers to the maximum dry unit weight reached in the laboratory according to the standard Proctor test and the modified Proctor test.

Table 1. Characteristics of soils

\begin{tabular}{|c|c|c|c|}
\hline & & Material 1 & Material 2 \\
\hline Descriptive designation & & Weak soil & Optimum performance soil \\
\hline Characteristic factor $(\mathrm{Fp})$ & & 0.51 & 0.51 \\
\hline Classification & & A-2-4(0) & A-2-4(0) \\
\hline Specific gravity & & 2.71 & 2.71 \\
\hline Liquid limit (\%) & & 19.4 & 20 \\
\hline Plasticity index (\%) & & 7.76 & 7.71 \\
\hline Compaction percentage (\%) & \multirow{2}{*}{ Before water content changes in soil } & $100(\mathrm{~S}-\mathrm{P})$ & $100(\mathrm{M}-\mathrm{P})$ \\
\hline Water content $(\%)$ & & $13.8(\mathrm{Sr} \approx 73 \%)$ & $10.3(\mathrm{Sr} \approx 77 \%)$ \\
\hline Compaction percentage (\%) & \multirow{2}{*}{ After water content changes in soil } & $99.8(\mathrm{~S}-\mathrm{P})$ & 99.4 (M-P) \\
\hline Water content (\%) & & $14.5(\mathrm{Sr} \approx 76 \%)$ & $10.8(\mathrm{Sr} \approx 80 \%)$ \\
\hline
\end{tabular}

The analysis of variance at a significance level of 0.05 , revealed no significant differences in the index properties between the weak soil and the optimum performance soil.

Table 2 shows the results of the compaction tests performed in the laboratory with a compactive effort of $600 \mathrm{~kJ} / \mathrm{m}^{3}$ (standard Proctor) and of $2700 \mathrm{~kJ} / \mathrm{m}^{3}$ (modified Proctor) for the soil. 
Table 2. Variation of maximum dry unit weight and optimum water content of the soil as a function of compactive effort

\begin{tabular}{lcc}
\hline & \multicolumn{2}{c}{ Proctor } \\
\cline { 2 - 3 } & Standard & Modified \\
\cline { 2 - 3 } Optimum water content $(\%)$ & 13.8 & 10.3 \\
Maximum dry unit weight $\left(\mathrm{kN} / \mathrm{m}^{3}\right)$ & 17.90 & 19.87 \\
\hline
\end{tabular}

Table 2 shows that, for the soil, the optimum water content determined with the standard Proctor test was higher than the one obtained with the modified Proctor test. This is in opposition with dry unit weight, as in the standard Proctor test the dry unit weight was smaller than the dry unit weight obtained with the modified Proctor test.

Figure 2 shows the design curves for CBR obtained with the soil used as base course of pavement; when dry unit weight was $19.87 \mathrm{kN} / \mathrm{m}^{3}$ (100\% of compaction percentage relative to the maximum dry unit weight obtained with the modified Proctor test), and saturation degree was $77 \%$ the CBR measured in the laboratory was $48.6 \%$. On the other hand, when the dry unit weight was $17.90 \mathrm{kN} / \mathrm{m}^{3}$ (100\% of the compaction percentage relative to the maximum dry unit weight obtained with the standard Proctor test), and saturation degree was $73 \%$ the CBR measured in the laboratory was $12.1 \%$.

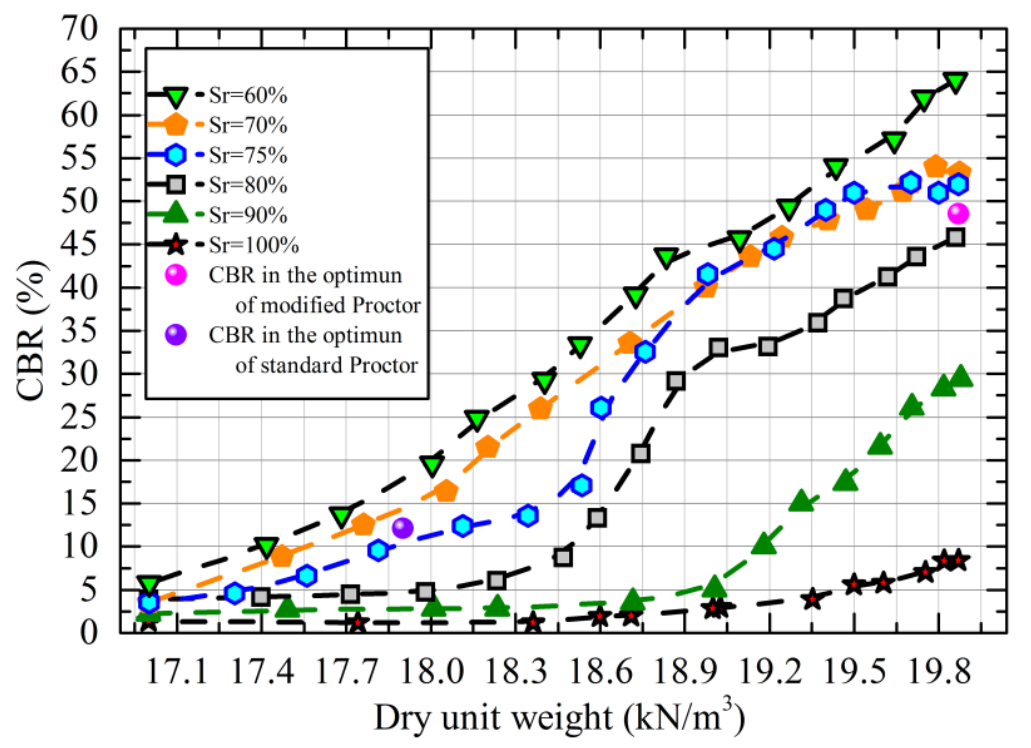

Figure 2. Design curves of CBR as a function of dry unit weight, for different saturation degrees and the compaction states (scatter points) of the soil measured in the optimum of Proctor's curves. Sr, saturation degree

Table 1 shows that, for the optimum performance soil, the compaction percentage measured (before water content changes in soil) at the construction site was $100 \%\left(19.87 \mathrm{kN} / \mathrm{m}^{3}\right)$ relative to the maximum dry unit weight obtained with the modified Proctor test, and according to the design curves (Figure 2) CBR was $48.6 \%$ for a saturation degree of $77 \%$. Table 1 also shows that, for the weak soil, the compaction percentage measured (before water content changes in soil) at the construction site was $100 \%\left(17.90 \mathrm{kN} / \mathrm{m}^{3}\right)$ relative to the maximum dry unit weight obtained with the standard Proctor test, and according to the design curves (Figure 2) CBR was $12.1 \%$ for a saturation degree of $73 \%$, and although was compacted, the CBR was minor than the minimum CBR required.

Figure 3 and 4 shows CBR design curves as function of compaction percentage for the soil used as base course of pavement and shows the scatter points that correspond to the state of the soil (compaction percentage and saturation degree) measured in situ after changing the water content conditions; it can be seen that the soil that was compacted with heavy equipment (and verified using the compaction percentage respect to modified Proctor, Figure 3 ) met the required conditions of mechanical performance $(\mathrm{CBR} \geq 25 \%)$. On the other hand, the soil used to fill the excavation (compacted with light equipment) see Figure 4, shows the scatter points that correspond to the state of the soil (compaction percentage and saturation degree) measured in situ after changing the water content conditions and whose compaction process was only verified using the compaction percentage (relative to the standard Proctor test, figure 4) did not meet the required conditions of minimum performance (even if is reached $100 \%$ of compaction percentage respect to standard Proctor test) and even less when the saturation degree increased.

Figure 3 shows that for $95 \%$ of compaction percentage (relative to the maximum dry unit weight obtained with the modified Proctor test), the material shows higher values than the minimum CBR required (CBR $\geq 25 \%$ ) for saturation degrees of $60,70,75$ and $80 \%$. 
Figure 4 shows that for $100 \%$ of compaction percentage (relative to the maximum dry unit weight obtained with the standard Proctor test) and a saturation degree of $76 \%$, the CBR was $8.7 \%$, representing a difference of $16.3 \%$ with respect of the minimum $\mathrm{CBR}$ required $(\mathrm{CBR} \geq 25 \%)$.

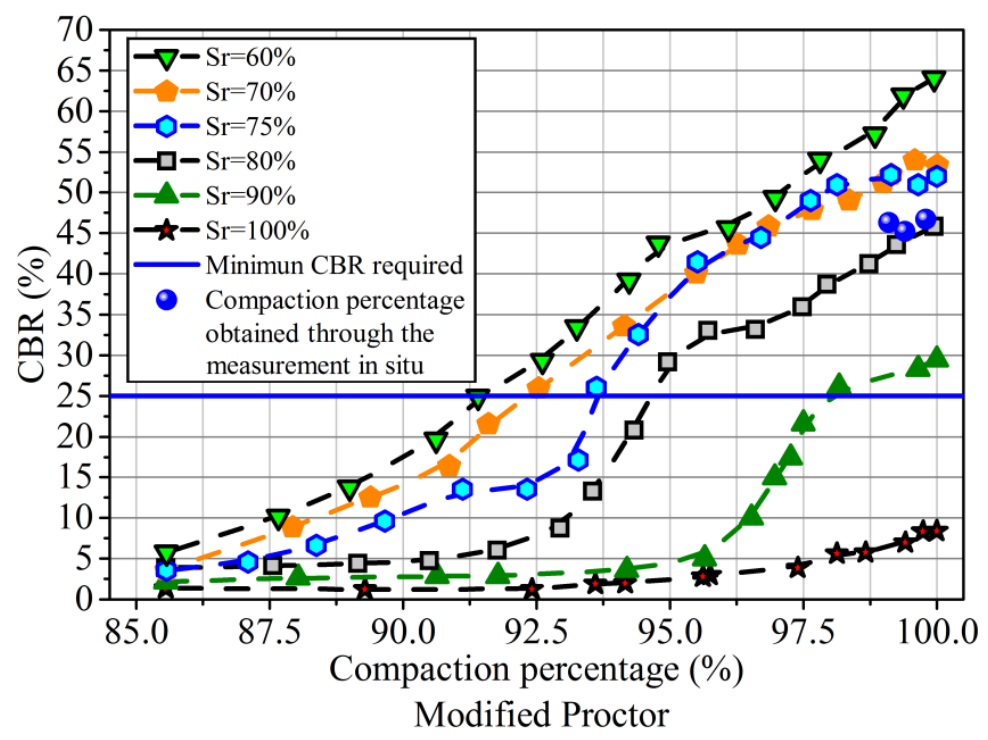

Figure 3. CBR as a function of compaction percentage for different isosaturation curves and the compaction states of the soil (scatter points) measured in situ after water change. Sr, saturation degree

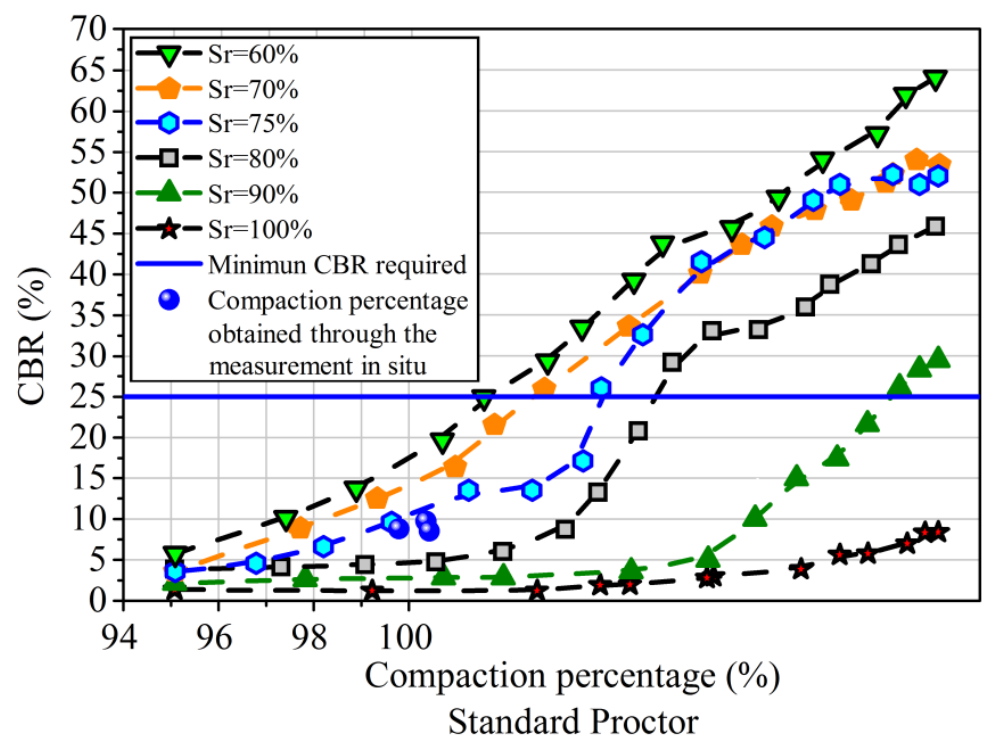

Figure 4. CBR as a function of compaction percentage for different isosaturation curves and the compaction states of the soil (scatter points) measured in situ after water change. Sr, saturation degree

\section{Results and Discussion}

In this study, the causes of the failure in the bearing capacity of a soil used as a base course of a concrete pavement were studied. The causes of the failure of the compacted soil were explained through quantitative data obtained in the laboratory from the interaction between CBR, saturation degree, and dry unit weight using the design curves of the RAMCODES methodology.

The particles of the weak soil and the optimum performance soil did not exhibit a crushing phenomenon. The fact that the particles were intact after they received the energy delivered by compaction is due to the high specific gravity of solids whose value was 2.71 .

The particle grain size and plasticity of the weak soil and the optimum performance soil were not statistically different. The characteristic factors of the materials were the same (Table 1 , characteristic factor $=0.51$ ), which implies that their mechanical behavior should be the same, but this was not the case.

The fact that the weak soil did not acquire the minimum bearing capacity expected after compaction with light 
vibrocompaction equipment is explained because the dry unit weight obtained did not provide the proper structure to the mass of soil to make it capable of resisting the minimum bearing capacity of the design (Figure 4). In construction site due to space limitations, it was necessary to use light equipment to compact the soil used for filling.

For compaction percentage of $94 \%$ (relative to the modified Proctor test), and water content conditions close to the optimum of the compaction curve (saturation degree of $80 \%$ ), the material meets the minimum CBR required for the design ( $C B R \geq 25 \%$ ). However, according to the traditional criterion of $95 \%$ of the compaction percentage (relative to the maximum dry unit weight obtained with the standard Proctor test), after change water content CBR was $8.7 \%$, and the mechanical response of the soil did not satisfy the minimum bearing capacity required (CBR $\geq 25 \%$ ). This means that even if the soil was compacted, it was not capable of resisting the expected load, in the conditions of water content and dry unit weight reached after compaction at the construction site (and even less after the change of water content). Moreover, according to the design curves, when the dry unit weight is kept constant and the saturation degree increases (Figure 2) the CBR value tends to decrease because water inside the soil mass does not contribute to the bearing capacity. According to Figure 3, when the dry unit weight is kept constant (100\% of compaction percentage relative to the maximum dry unit weight obtained with the standard Proctor test) and the water content of the weak soil changes, the saturation degree changes in consequence from 73 to $76 \%$, so the CBR was $8.7 \%$. On the other hand, in the optimum performance soil, when the dry unit weight is kept constant (compaction percentage of $99.4 \%$ modified Proctor, figure 2 ), when water content changes and the saturation degree changes in consequence (from 77 to $80 \%$ ), the CBR was close to $45 \%$.

Hypothetically, if the compaction percentage considered to verify the quality control of compaction process was $95 \%$ (relative to the maximum dry unit weight obtained with the standard Proctor test), the CBR was 3.7\% far below to the minimum CBR required. This show an evident risk generated using only the criterion of the minimum compaction percentage (traditionally $95 \%$ of compaction percentage).

A compaction percentage of $94 \%$ (relative to the maximum dry unit weight obtained with the modified Proctor test) and a saturation degree of $80 \%$ could be considered the minimum compaction percentage that meets the expected mechanical performance $(\mathrm{CBR} \geq 25 \%)$. This means that, independently of the compaction equipment used at the construction site (heavy equipment or light equipment), achieving $94 \%$ of the compaction percentage (relative to the maximum dry unit weight obtained with the modified Proctor test) is desirable. However, experts working in the field, who possess knowledge about the theory of compaction process, know the difficulties of achieving high dry unit weights with light compaction equipment. Thus, a potentially idoneous solution would be to improve the material with cement, polymer, or to substitute the material with other material of higher bearing capacity.

Although the soil used to fill the excavation (characteristic factor of 0.51) was compacted, and reach the maximum dry unit weight obtained with the standard Proctor test (compaction percentage of $100 \%$ ), it did not reach the minimum CBR required, and even less when there were changes in water content (Figure 3).

When the criterion of the minimum compaction percentage was solely used for quality control of the compacted soil, the company in charge of the compaction assumed that using the maximum dry unit weight (obtained in the laboratory by the standard Proctor test) was an adequate procedure to control the compaction percentage at the construction site. This assumption was made in order to be in concordance with the compactive effort delivered to the soil in the laboratory and at the construction site. The sole use of the compaction percentage (maximum dry unit weight obtained with the standard Proctor test) to achieve a CBR that theoretically should be close to the minimum required for the soil used as filling was the cause of the failure.

\section{Conclusion}

According to analysis of variance, the material compacted with light vibrocompaction equipment (weak soil) and the material compacted with heavy vibrocompaction equipment (optimum performance soil), were not statistically different in terms of particle size and plasticity properties. When the dry unit weight is kept constant, the saturation degree increases and $\mathrm{CBR}$ decreases.

According to the design curves, the weak soil (compacted with light equipment) at the optimum densification potential (maximum dry unit weight and optimum water content) it did not have the minimum bearing capacity required ( $\mathrm{CBR} \geq 25 \%$ ); moreover, if water content (saturation degree) changed, the bearing capacity continued to decrease.

The failure of the material compacted with light equipment was due to the soil not reaching an adequate mechanical performance ( $C B R \geq 25 \%)$, and to changes in saturation degree due to changes in water content. The failure of the soil was not anticipated at the construction site, because using only the criterion of the minimum compaction percentage, the selection of the maximum dry unit weight, was an erroneous decision for controlling the performance of material through the minimum compaction percentage of the soil. The erroneous choice of the densification potential (optimum water content and maximum dry unit weight) for the determination of the compaction percentage, supposedly to be in concordance to the type of equipment used at the construction site (historical focus), was the cause of the soil failure. 
At the construction site, it would be necessary to use another material (or the same material improved with cement or other substances, such as polymers) to fill the excavation, so that the mechanical performance required (CBR $\geq 25 \%)$ is achieved with a compaction percentage of $95 \%$ of the standard Proctor test.

For compaction percentages equal or higher than $95 \%$ (relative to the maximum dry unit weight obtained by the modified Proctor test) and saturation degrees $60-80 \%$, the bearing capacity of the soil compacted with heavy vibrocompaction equipment was higher than the minimum required (CBR $\geq 25 \%$ ). A compaction percentage of $94 \%$ (relative to the maximum dry unit weight obtained with the modified Proctor test) with a saturation degree of $80 \%$ (according to the design curves) could be considered the minimum compaction percentage that meets the minimum CBR required.

Using the minimum compaction percentage to control the quality of compacted soils, the information (water content and dry unit weight) is limited to the analysis of the mechanical performance when the saturation degree and the dry unit weight of the compacted soil change. The criterion of the minimum compaction percentage is suboptimal for the control of the mechanical response of compacted soils.

Using the commonly pre-established minimum compaction percentage (traditionally $95 \%$ of the maximum dry unit weight of the standard or modified Proctor tests), the failure of the compacted soil could not be anticipated because the expected mechanical performance was unknown.

This study clearly illustrates how the design curves of the RAMCODES methodology provide technical and quantitative evidence of the influence of the dry unit weight and the saturation degree on the mechanical performance of compacted soils; therefore, design curves could be used in forensic geotechnical evaluation, in addition to their use for the design of compacted soils.

\section{Acknowledgments}

This work was supported by Consejo Nacional de Ciencia y Tecnología (CONACYT), Programa Institucional de Formación de Investigadores (PIFI), Instituto Politécnico Nacional (IPN), Centro de Investigación en Ciencia Aplicada y Tecnología Avanzada (CICATA-Legaria), in collaboration with Universidad Autónoma Gabriel René Moreno (UAGRM), RONERFE Ltda., "Planta de mezclado de materiales Urubó", "Colinas del Urubó", and Eng. Mario Foianini and his family. Authors wish to thank to all the staff involved and all those whose collaboration was invaluable in this research.

\section{Funding}

This work was economical supported by Consejo Nacional de Ciencia y Tecnología (CONACYT) and Programa Institucional de Formación de Investigadores (PIFI).

\section{References}

[1] Daniel, David E., and Benson, Craig H. "Water content-density criteria for compacted soil liners." Journal of Geotechnical Engineering. American Society of Civil Engineers 116 (12) (December 1990): 1811-1830. doi: 10.1061/(asce)07339410(1990)116:12(1811).

[2] Davis, Tim. "Geotechnical testing, observation, and documentation” (2008). doi: 10.1061/9780784409497.ch04.

[3] Ganju, E., Kim H, Prezzi M., Salgado, R. and Siddiki, NZ. "Quality assurance and quality control of subgrade compaction using the dynamic cone penetrometer.” International Journal of Pavement Engineering Civil Engineering Journal 19 (2016): 966-975. doi: 10.1080/10298436.2016.1227664.

[4] Lommler, John C. “Geotechnical Problem Solving” (March 9, 2012). doi:10.1002/9781119968429.

[5] Fang, Hsai-Yang. "Foundation Engineering Handbook" (1991). doi:10.1007/978-1-4757-5271-7.

[6] Herrmann, Jonathan G., and Elsbury, Bill R. "Influential factors in soil liner construction for waste disposal facilities." Geotechnical practice for waste disposal'87 (1987) American Society of Civil Engineers: 522-536.

[7] Montejo-Fonseca, Alfonso. "Ingeniería de pavimentos para carreteras Tomo I" (2002). Ediciones y publicaciones Universidad Católica de Colombia.

[8] Wu, Jason Y., Kaiming Huang, and Munira Sungkar. "Remediation of Slope Failure by Compacted Soil-Cement Fill." Journal of Performance of Constructed Facilities 31, no. 4 (August 2017): 04017022. doi:10.1061/(asce)cf.1943-5509.0000998.

[9] ASTM D698-12e2. "Standard Test Methods for Laboratory Compaction Characteristics of Soil Using Standard Effort (12,400 ftlbf/ft3(600 kN-m/m3))”. ASTM International (2012). doi: 10.1520/d0698-07.

[10] ASTM D1557-09. "Standard Test Methods for Laboratory Compaction Characteristics of Soil Using Modified Effort (56,000 $\mathrm{ft}-\mathrm{lbf} / \mathrm{ft} 3(2,700 \mathrm{kN}-\mathrm{m} / \mathrm{m} 3))$ ). ASTM International (2009). doi: 10.1520/d1557-09.

[11] COVENIN 2000-1:2009. "Norma Técnica Fondonorma. Carreteras, Autopistas y Vías Urbanas. Especificaciones y Mediciones”. 
Fondo para la Normalización y Certificación de la Calidad, FONDONORMA (2009). Venezuela.

[12] Sánchez-Leal, F.J., Garnica Anguas, P., Gómez López, J.A., and Pérez García, N. "RAMCODES: Metodología racional para el análisis de densificación y resistencia de geomateriales compactados”. Publicación Técnica 200 (2002).

[13] Sánchez-Leal, F.J. "Interpretation of CBR-test results under the shear-strength concept of unsaturated soil mechanics." Proceedings of the third international conference on unsaturated soils (USAT 2002) (2002).

[14] Sánchez-Leal, F.J., and de Campos, Jucá. "Correlation of maximum density and optimum water content with index properties” (2002).

[15] Taylor, Donald W. “Fundamentals of Soil Mechanics.” Soil Science 66, no. 2 (August 1948): 161. doi:10.1097/00010694194808000-00008.

[16] Proctor, R. "Fundamental principles of soil compaction.” Engineering News-Record 111 (13) (1933).

[17] Marinho, F A M, O M Oliveira, H Adem, and S Vanapalli. "Shear Strength Behavior of Compacted Unsaturated Residual Soil." International Journal of Geotechnical Engineering 7, no. 1 (January 2013): 1-9. doi:10.1179/1938636212z.00000000011.

[18] Zhang, T., Cui, Y., Lamas-Lopez, F., Calon, N. and Costa, D’Aguiar. "Compacted soil behaviour through changes of density, suction, and stiffness of soils with remoulding water content." Canadian Geotechnical Journal 55 (February 2017): 182-190. doi: $10.1139 /$ cgj-2016-0628.

[19] Sánchez-Leal, Freddy J. “Gradation Chart for Asphalt Mixes: Development.” Journal of Materials in Civil Engineering 19, no. 2 (February 2007): 185-197. doi:10.1061/(asce)0899-1561(2007)19:2(185).

[20] Sánchez-Leal, Freddy J., Paul Garnica Anguas, Michael Larreal, and Diana B. López Valdés. "Polyvoids: Analytical Tool for Superpave HMA Design." Journal of Materials in Civil Engineering 23, no. 8 (August 2011): 1129-1137. doi:10.1061/(asce)mt.19435533.0000275.

[21] ASTM D6913. "Standard test methods for particle-size distribution (gradation) of soils using sieve". ASTM International (2017). doi: 10.1520/d6913_d6913m-17.

[22] ASTM D4318. "Standard Test Methods for Liquid Limit, Plastic Limit, and Plasticity Index of Soils". ASTM International (2010). doi: 10.1520/d4318-10.

[23] ASTM D854 -06e1. "Standard Test Methods for Specific Gravity of Soil Solids by Water Pycnometer". ASTM International (2006). doi: 10.1520/d0854-06e01

[24] ASTM D3282-15. "Standard Practice for Classification of Soils and Soil-Aggregate Mixtures for Highway Construction Purposes”. ASTM International (2004). doi: 10.1520/d3282-93r04e01

[25] ASTM D2216-10. "Standard Test Methods for Laboratory Determination of Water (Moisture) Content of Soil and Rock by Mass". ASTM International (2015). doi: 10.1520/d2216-10.

[26] ASTM D1556. "Standard Test Method for Density and Unit Weight of Soil in Place by the Sand-Cone Method". ASTM International (2015). doi: 10.1520/d1556_d1556m-15.

[27] Jiju, Antony. "Design of experiments for engineers and scientists, Second Edition" (2014). doi: 10.1016/b978-0-08-0994178.00002-x.

[28] ASTM D1883-99. "Standard Test Method for California Bearing Ratio (CBR) of Laboratory-Compacted Soils". ASTM International (2016). doi: 10.1520/d1883-16. 